\section{O agente comunitário de saúde: formação, inserção e práticas}

\author{
Community health agents: training, involvement, \\ and practices
}

\footnotetext{
${ }^{1}$ Centro de Ciências da Vida Pontifícia Universidade Católica de Campinas,

Campinas, Brasil.

2 Coordenadoria Setorial

das Relações de Trabalho,

Secretaria Municipal

de Saúde de Campinas,

Campinas, Brasil.

3 Faculdade de Ciências

Médicas, Universidade

Estadual de Campinas,

Campinas, Brasil.

Correspondência E. P. L. Nascimento Faculdade de Enfermagem Centro de Ciências da Vida, Pontifícia Universidade Católica de Campinas. Rua Barreto Leme 2540, apto. 601, Campinas, SP 13025-085, Brasil.

betlelo@uol.com.br
}

\section{Abstract}

The aim of this study was to identify contributions by the training course for community health agents provided by the Municipal Health Secretariat in Campinas, São Paulo State, Brazil, from 2001 to 2003, to evaluate their assessment concerning its role in the community, and to identify its impact on their professional practice. This was a qualitative health study using the focus group technique, and the empirical data were analyzed with thematic content analysis. Training of community health agents aimed to include a professional capable of reflecting on and intervening in the local reality. The Family Health Program - Paidéia included community health agents in the health system to help reorganize the activities in the primary health care units and consolidate the model. The training allowed community health agents to act as educational protagonists, producing emancipative knowledge and encouraging reflection and the capacity for critical analysis, including daily practice as a key determinant of their learning process in the search for solutions to the community's problems.

Community Health Services; Health Personel; Family Health Program
Elisabet Pereira Lelo Nascimento 1,2 Carlos Roberto da Silveira Correa ${ }^{3}$

\section{Introdução}

O Sistema Único de Saúde (SUS) é fruto de uma luta política da qual participaram movimentos populares, associações de moradores, profissionais de saúde, que, no movimento da reforma sanitária, buscaram a construção de uma agenda de discussão positiva de direitos sociais. No setor saúde esse processo tem significado a defesa e a construção de um sistema universal e includente, pluralista e democrático pela municipalização dos serviços. Desde a sua concepção ele tem, entre suas características mais importantes, o controle social, a gestão única em todas as esferas do governo, pautando-se nos eixos da eqüidade, universalidade e integralidade.

A partir da experiência bem sucedida do Programa de Agentes Comunitários de Saúde (PACS), criado em 1990, o Programa Saúde da Família (PSF) foi concebido pelo Ministério da Saúde em 1994. O PSF vem se consolidando como uma estratégia de fortalecimento do SUS e, entre as suas ações, está a de auxiliar na transformação da estrutura dos serviços de saúde, o que inclui o planejamento e a programação da oferta de serviços a partir do enfoque epidemiológico, incluindo a compreensão dos múltiplos fatores de risco à saúde, e a possibilidade de intervenção sobre os mesmos com estratégias como a promoção da saúde 1 .

A implementação do PSF ocorreu de maneira bastante diversificada em todo o país e um dos 
fatores que contribuíram para isso foi o fato de ele trazer como um de seus principais eixos a territorialização que orienta, tanto o olhar como as intervenções que são propostas para a resolução dos problemas encontrados na área coberta de cada uma das equipes do PSF e, em virtude dessas diferenças, diversos modelos de atuação do PSF vêm sendo criados, bem como uma multiplicidade de experiências na formação do agente comunitário de saúde, em razão das especificidades regionais encontradas.

Campinas, Estado de São Paulo, Brasil, experimentou diversos modelos assistenciais na construção do sistema de saúde, destacandose, na implantação do SUS. Mais recentemente, a Secretaria Municipal de Saúde (SMS) utilizou como estratégia para o fortalecimento do SUS o PSF-Paidéia, iniciando em toda a rede, discussões sobre os pressupostos deste projeto que apresentava como desafio a mudança de modelo de atenção, em uma cidade de grande porte com um sistema instalado e funcionando.

Segundo Campos 2, havia evidências de falta de recursos em regiões específicas em determinadas áreas de atendimento, principalmente em relação à atenção à saúde do adulto. A organização dos serviços não cumpria com os objetivos da atenção primária, promovendo longas filas de espera e sobrecarga de trabalho, conformando um diagnóstico que apontava a incapacidade do sistema na absorção da demanda e no atendimento às necessidades básicas de saúde da população. Existia baixa capacidade de trabalho de promoção à saúde e atenção no domicílio ou na comunidade, com a hegemonia de uma clínica com pouca potencialidade na resolução de problemas de saúde.

É relevante destacar que, em 1998, o Movimento Popular de Saúde de Campinas e parte dos gestores da SMS, opuseram-se à implantação do PACS por defenderem que a expansão de recursos humanos deveria se dar pela contratação de profissionais de saúde qualificados e não pela incorporação de agente comunitário de saúde, cuja função prioritária seria o desenvolvimento de educação em saúde. Ressaltaram ainda que as características do sistema de saúde de Campinas em relação aos municípios localizados nas regiões Norte e Nordeste do país demandariam outras estratégias de aprimoramento do acesso da população aos serviços de saúde que transcenderiam o potencial do PACS. Diante de tal cenário político, o Conselho Municipal de Saúde não aprovou a implantação desse programa e procedeu à restituição dos recursos financeiros destinados para esse fim ao Ministério da Saúde.

O PSF-Paidéia trouxe características conceituais próprias e buscando superar alguns limites da clínica e dos modos como os serviços se organizavam para produzir a atenção à saúde e a incorporação de dois novos profissionais na rede básica: o médico generalista e o agente comunitário de saúde profissional, esse que deveria ser capacitado para atuar junto às equipes de referência (médico generalista, enfermeiro, dentista, atendente de consultório dentário, auxiliar de enfermagem e agente comunitário de saúde), ampliando a capacidade das unidades básicas de saúde intervirem na comunidade e nos domicílios. Tendo como diretrizes 2 (p. 16) "acolhimento, responsabilização, gestão participativa, vínculo, clínica ampliada, cadastro, capacitação e controle social".

O PSF-Paidéia apresentava, em relação ao programa proposto pelo Ministério da Saúde, uma forma alternativa na organização das equipes de referências das unidades básicas de saúde, dando-lhes um formato em que todos os trabalhadores dos serviços de atenção básica eram incorporados ao novo modelo assistencial. O número de equipes de referência foi determinado pela adscrição da clientela. No início foram constituídas 140 equipes e a função principal dos agentes comunitários de saúde foi pautada em dar voz à comunidade, sendo elo entre os trabalhadores das unidades básicas e a comunidade.

A SMS organizou o processo seletivo simplificado para a contratação do profissional agente comunitário de saúde elaborando o edital a partir das definições descritas pelo Ministério da Saúde e Conselho Municipal de Saúde de Campinas, que desde 1998 já vinham discutindo as atribuições desse profissional, sendo os requisitos necessários 3 (p. 23): "ter idade mínima de 18 anos completos; documento de identidade; carteira de trabalho; ensino fundamental; residir na área que irá atuar e estar quites com o serviço militar".

\section{O preparo da capacitação}

A SMS desencadeou um amplo e progressivo processo de capacitação, com apoio das universidades locais (Pontifícia Universidade Católica de Campinas - PUC-Campinas e Universidade Estadual de Campinas - UNICAMP) e o pólo de capacitação de saúde da família, tomando como foco a equipe de referência, buscando ampliar a clínica e alterar o processo de trabalho nas unidades básicas de saúde. Para tanto, o Centro de Educação dos Trabalhadores da Saúde (CETS) responsabilizou-se pelas capacitações, entendendo que, para que esses objetivos fossem alcançados, dependeria de profissionais formados e capacitados para operar numa ótica que integrasse aspectos sociais e subjetivos à formação biológica clássi- 
ca, que necessariamente se modifica, ampliando o núcleo de conhecimentos exigidos em função dos novos campos de intervenção voltados para a inter e transdisciplinariedade 4 .

Sendo assim, parte da equipe técnica do CETS construiu uma proposta de capacitação para o agente comunitário de saúde do Município de Campinas a partir das diretrizes do PSF-Paidéia e das seguintes experiências e documentos: curso para agentes comunitários de saúde do Instituto de Pesquisas Especiais para a Sociedade (IPES); pólo de capacitação para agentes comunitários de saúde da Diretoria Regional de Saúde XII (DIRXII) e documentos produzidos pelo Ministério da Saúde. Para o fortalecimento desse processo de capacitação, além dessas instituições, a SMS efetivou parceria com a UNICAMP, buscando agregar saberes e práticas dos órgãos formadores e dos serviços de saúde, estabelecendo assim um intercâmbio e validação através da certificação.

O grande desafio foi preparar os agentes comunitários de saúde de maneira que atendesse às diretrizes do PSF-Paidéia de forma abrangente e organizada, adotando uma ação educativa crítica, capaz de referenciar-se nas práticas e nas transformações políticas, tecnológicas e científicas relacionadas à saúde e de assegurar o domínio de conhecimentos e habilidades específicas para o desempenho de sua função. Para tanto, propusemos desenvolver uma prática educativa pautada no "abandono da estreiteza burocrática de procedimentos escolarizantes" 5 (p. 28), tendo como opção percorrer o caminho da pedagogia de Paulo Freire.

O conteúdo programático elaborado a partir da concepção do papel do agente comunitário de saúde trazia os seguintes núcleos temáticos 3 (p. 18): "integração do grupo; trabalho em equipe; reconhecimento do território; educação e saúde; atribuições do agente comunitário de saúde; políticas de saúde no Brasil; família; conceito de território; diagnóstico; cadastro; o usuário como portador de direitos; participação e mobilização comunitária; ciclo vital (infância, adolescência, maturidade, e terceira idade); ecossistema e saúde ambiental".

A SMS, objetivando qualificar o processo de formação dos agentes comunitários de saúde, realizou junto à UNICAMP a capacitação dos instrutores/capacitadores envolvidos, através da Escola de Extensão da UNICAMP (EXTECAMP), com os seguintes temas: ética; as necessidades de saúde; saber enxergar; núcleos de saúde coletiva e vigilância em saúde; o que é um problema de saúde pública; políticas sociais e experiências do Município de Pedreira, São Paulo, Brasil, em PSF. Além dessa forma, os instrutores receberam capacitação pedagógica e técnica para que pu- dessem se apropriar da metodologia e do conteúdo programático que seria aplicado durante a capacitação do agente comunitário de saúde.

Adotamos a metodologia da problematização 6,7 , que tem como objetivo potencializar a aprendizagem do aluno, participante e agente da transformação social, para detectar os problemas reais e buscar para eles soluções originais. Tal pedagogia vem sendo desenvolvida desde a década de 80, quando iniciou a formação em serviço de pessoal de nível médio e elementar, através do Larga Escala 8 que propõe uma nova forma de organizar o trabalho pedagógico nas instituições de saúde, e realizar uma reflexão e discussão conjunta de alguns problemas que envolvam a tarefa de ensinar do instrutor/docente, como alternativa adequada e coerente para a qualificação de sua força de trabalho.

A avaliação do aproveitamento da capacitação foi realizada em três momentos distintos: (1) durante o período de concentração, em que o instrutor acompanhava o desempenho do aluno durante o desenvolvimento das atividades através de instrumento próprio; (2) em campo o aluno desenvolvia atividades práticas pertinentes a cada tema, com supervisão da equipe de referência e apoiadores, sendo registrada em fichas específicas e (3) avaliação dissertativa de um estudo de caso, abrangendo o conteúdo programático oferecido durante a capacitação.

O processo de formação foi preparado para 500 agentes comunitários de saúde, organizados em turmas de aproximadamente 30 alunos com carga horária de 8 horas semanais de concentração e em média 16 horas de dispersão por tema, totalizando 486 horas. A operacionalização ocorreu de forma descentralizada e foi executada pelos Distritos de Saúde, tendo esses ampla liberdade para re-adequar o conteúdo programático a partir de suas necessidades e realidades locais.

Em 2003, o Departamento de Gestão da Educação na Saúde (DGES), da Secretaria da Gestão do Trabalho e da Educação na Saúde, do Ministério da Saúde, que é responsável pela proposição e formulação das políticas relativas à formação e educação permanente dos trabalhadores de saúde, inicia um investimento na Política de Educação Profissional em Saúde, tanto na ampliação da escolaridade dos trabalhadores como na sua profissionalização (formação) e educação permanente 9 . Nesse sentindo, vem trabalhando na perspectiva da habilitação técnica em itinerário para o conjunto de cursos de nível técnico da área da saúde, especialmente no caso do agente comunitário de saúde, indo ao encontro do status de profissão adquirido com a homologação da Lei $n^{o}$. 10.507, de 10 de julho de 2002. 
Considerando a relevância do trabalho desse profissional no PSF-Paidéia, a presente pesquisa foi desenvolvida com objetivo de analisar a inserção do agente comunitário de saúde nas unidades básicas de saúde e de identificar se a formação oferecida pela SMS contribuiu para a construção das habilidades e competências desses profissionais, por meio de realização da técnica de grupo focal e análise de conteúdo temática.

\section{O caminho percorrido}

Atualmente, a SMS conta com 585 agentes comunitários de saúde, distribuídos em 141 equipes de referência. Destes, 292 concluíram a formação oferecida em parceria com a UNICAMP. E estão alocados nos cinco Distritos de Saúde do Município de Campinas. Sendo assim, sorteamos dez representantes dos agentes comunitários de saúde de cada Distrito de Saúde, para participar dos cinco grupos focais 10,11 , totalizando 49 sujeitos.

As sessões de grupo foram realizadas no período de junho e julho de 2006, com utilização de um roteiro orientador para a discussão (prática atual dos agentes comunitários de saúde, como aprenderam a desenvolver essa prática, o significado da capacitação e a sua contribuição na prática como agentes), de acordo com o objetivo da pesquisa. As sessões grupais tiveram em média duas horas de duração e contamos com presença de um moderador e um observador, sendo a sessão grupal gravada com anuência dos participantes.

Em respeito ao anonimato dos agentes comunitários de saúde que participaram dos grupos focais, usaremos ao longo do texto as letras Ga, $\mathrm{Gb}, \mathrm{Gc}, \mathrm{Gd}$ e Ge para identificar os cinco grupos realizados e para especificar os sujeitos, cada um receberá um número 1, 2, 3, 4, 5, 6, 7, 8 e 9.

Realizamos a análise das evidências trazidas por meio da análise temática 12,13 , que consistiu em desmembramento do texto transcrito em categorias, evidenciando os núcleos temáticos e sua freqüência, organizadas em três etapas: préanálise - onde ocorreu a organização e sistematização das idéias, sendo realizada uma leitura flutuante, constituição do corpus, formulação das hipóteses e elaboração dos indicadores; $a$ exploração do material - para efetuar a classificação e, por fim, realizamos o tratamento dos dados obtidos e a interpretação.

O projeto de pesquisa foi aprovado pelo Comitê de Ética de Pesquisa da Faculdade de Ciências Médicas da UNICAMP, em conformidade com a Resolução no. 196/96 do Conselho Nacional de Saúde, no mês de dezembro de 2005.
Os participantes do estudo foram orientados em relação aos objetivos e procedimentos da pesquisa, tendo assinado o Termo de Consentimento Livre e Esclarecido.

\section{Resultados e discussão}

Considerando a formação dos agentes comunitários de saúde como um dos pilares que sustenta a inserção e as práticas desenvolvidas por esses profissionais, buscamos significados nos conteúdos apresentados, seguindo os critérios de representatividade e exaustividade 12 , e encontramos os seguintes eixos temáticos: formação, inserção e práticas.

A formação do agente comunitário de saúde trazia uma grande expectativa em relação ao papel que esse profissional deveria desempenhar junto às equipes de referência, ou seja, contribuir para que o paciente e familiares se apropriassem de conhecimentos e de práticas que lhes foram progressivamente retirados pelo poder das corporações e pelo discurso técnico e ainda apoiar o desenvolvimento integral das pessoas e comunidades, mobilizando o potencial desses agrupamentos e estimulando o trabalho intersetorial 2 .

\section{A formação}

O roteiro proposto para os grupos focais evocou, inicialmente, a prática dos agentes comunitários e, a partir daí, como eles encontravam identidades entre essa prática e a capacitação oferecida pela instituição.

O projeto pedagógico elaborado permitiu ao educador (instrutor) assumir um papel de mediador da aprendizagem, desafiando e motivando os agentes comunitários de saúde a assumirem o papel de sujeitos educativos, produzindo um conhecimento emancipatório, estimulando a reflexão e a capacidade de análise e de crítica.

“Eu acho que a capacitação foi a base. Dali pra frente foi cada um vendo a sua forma de trabalho. E sua ação mediante as dificuldades, dos problemas nas situações enfrentadas, mas acho que foi a nossa base (...) e depois da capacitação muita coisa a gente aprendeu também, e cada um tomou aí a sua forma de trabalho, o jeito de trabalhar. Eu acho que foi muito válido" (Ga3).

A parceria junto à UNICAMP resultou, dentre outras ações, em palestras ministradas por professores da instituição, com objetivo de complementar a qualificação dos agentes comunitários de saúde. Porém, há falas de que a forma como foi efetuada não correspondeu com as expectativas desse profissional. 
"As aulas que a gente tinha na UNICAMP também era bem desgastante, era maçante. É porque era assim, os primeiros professores, eles davam aulas pra gente, como se eles tivessem dando aulas pra universitários. Então, pouca coisa a gente conseguia captar, era totalmente fora da realidade. O tema era bom, quando chegava pra nós o tema, a gente falava assim (...) esse vai ser bom, mas quando chegava, o jeito de passar é que era ruim, inadequado, a gente não entendia. Tinha gente que dormia na cadeira" (Ga7).

$\mathrm{O}$ enunciador do curso ministrado para os agentes comunitários de saúde foi o estado, no caso o Município de Campinas e a UNICAMP, além de uma organização não governamental. O conteúdo estava repleto de deveres a serem seguidos pelo agente comunitário de saúde, relacionados à dengue, tuberculose, visita a faltosos, vigilância etc. $\mathrm{O}$ agente comunitário de saúde aprendeu, em diferentes momentos, diferentes formas de como ele deveria ser. O discurso dos agentes comunitários de saúde mostra outra realidade, a necessidade que ele tem de fugir desse dever, ele enfrenta o devir. O devir participa da formação do agente comunitário de saúde. Ele conseguiu reconhecer a importância da subjetividade em seu trabalho 14, e daí para o SUS, distante da idéia do dever aprendido no curso de formação, e mais diferente ainda daquele da UNICAMP.

\section{A inserção nas equipes de saúde}

O fato de realizarmos a capacitação dos agentes comunitários de saúde separadamente dos demais membros da equipe, potencializou a dificuldade de inserção desses profissionais nas equipes das unidades básicas de saúde e o desconhecimento da sua função.

“...Ou seja, na nova capacitação, que alguns membros da equipe pudessem participar. A equipe, a enfermagem, os médicos, eles tiveram uma capacitação em saúde da família. Nós não sabemos o que eles vivenciaram, o que aprenderam lá, e algumas vezes eles não sabem exatamente o que viemos fazer também" (Gb2).

Os auxiliares de enfermagem sentiram-se ameaçados com a incorporação do agente comunitário de saúde na unidade básica, por desconhecerem o seu papel. Em estudo realizado por Nascimento 15 , essa ameaça está presente entre os auxiliares de enfermagem em relação às enfermeiras, também pelo desconhecimento da função de novos profissionais dentro da unidade de saúde.

"No início houve até um pouco de rejeição lá do nosso trabalho dentro das unidades (...) porque no começo, a gente ouviu muito falar que as pesso- as se sentiam ameaçadas. Quando os agentes entraram, ninguém sabia direito, de repente entrou aquele monte de agente no centro de saúde, mas o que que eles vão fazer? Por que eles estão aqui? Isso muito também do pessoal da enfermagem, eles se sentiam ameaçados, achavam que a gente tava ali pra tomar o lugar deles. E aquilo com o decorrer do tempo, eles viram que não é nada disso, foi definindo as funções" (Gc1).

Com o passar do tempo, o agente comunitário de saúde foi construindo junto com a equipe a sua função, ocupando o lugar de articulador entre a comunidade e a equipe de saúde, ampliando o poder de atuação junto à população e qualificando a assistência prestada. A equipe de saúde hoje reconhece o trabalho desse profissional sendo que, às vezes, há até um exagero de ações atribuídas a ele.

“...No começo, houve aquela coisa assim da não aceitação, mas hoje tudo é o agente de saúde, eles procuram o agente de saúde não importa por que que seja, procura o agente de saúde. Nós somos a referência dentro do centro de saúde, porque somos nós que conhecemos cada um na sua micro área (...). E às vezes é até algo que eles podem estar resolvendo, que não tem nada a ver com a gente, mas eles procuram o agente de saúde" (Gd6).

As falas evidenciaram que o agente comunitário de saúde foi visto como ameaça pelas equipes de saúde. Essa ameaça pode ser associada com o papel de agente instituinte que o agente comunitário de saúde passou a desempenhar, frente ao papel instituído das equipes de saúde.

\section{As práticas}

Ao analisarmos as práticas dos agentes comunitários de saúde nas unidades básicas de saúde identificamos que há uma gama de atividades desenvolvidas que combinam com o objetivo da incorporação desse profissional às equipes de referência: visita domiciliar, participação em grupos educativos (hipertensos, diabéticos, gestantes, recém-nascidos etc.), vigilância à dengue, cadastro de renda mínima, busca ativa de faltosos, trabalho comunitário, cadastramento, dentre outros. Por outro lado, desempenham também atividades administrativas não relacionadas ao seu núcleo de conhecimento, sendo estas funções efetivadas por deficiência de recursos humanos e por desconhecimento da função desse profissional por parte dos outros profissionais da equipe. Conforme relato de um agente comunitário de saúde.

"Agora tem que ficar na fila, tem que ficar na recepção, tem que ficar na coleta, porque não tem funcionário. (...) os próprios funcionários que trabalham dentro do centro de saúde, que exigem 
que a gente esteja ajudando eles. Eles exigem um pouco isso" (Ga5).

Embora isso ocorra com freqüência, os agentes comunitários de saúde não concordam com essa situação e buscam constantemente mostrar qual é o seu papel, isto é, qual é o espaço que devem ocupar dentro da equipe, contando, às vezes, com a ajuda do Conselho Local de Saúde para redirecionar a sua função.

"Nós temos agentes de saúde que dificilmente faz a função dele, mais é lá dentro mesmo (...). A função não é mesmo do agente, o pessoal estava cobrando, aí o Conselho Local cobrou e aí resolveram tirar ela da função administrativa" (Gb9).

É esperado que o agente comunitário de saúde seja protagonista na construção de vínculos entre a comunidade, as pessoas e a família com os serviços de saúde e que intermediam o saber (prática biomédica) e a cultura da sociedade (território no qual trabalha). Nesse sentido o seu trabalho tem sido pautado em fortalecer a relação entre a população e a equipe de saúde, como manifestou um dos agentes comunitários de saúde.

"Lá na unidade a gente tem pessoas que estão na recepção só pra dizer: 'não tem médico, ou tem médico!'. A nossa visão é outra, porque a gente sabe que o paciente nem sempre quer médico! Às vezes ele quer só uma atenção! Ele está passando por dificuldade e a gente consegue ter essa outra visão. (...) eu fico olhando aquelas crianças pisando no esgoto, com situação difícil (...) e a dona Lucineide às vezes não tem nem o que comer em casa, aí quando a gente pode, a gente ajuda de um jeito ou de outro. Na verdade quem faz o vínculo com a família, com a comunidade é o agente. (...) outras vezes o paciente passa por consulta médica, passa pela enfermagem, passa pela farmácia, aí chega lá pro agente de saúde: você me explica isso daqui! Eu não entendi. Porque tem aquela distância, então ela se sente mais próximo de um agente de saúde pra perguntar, tem menos tabu, menos vergonha. Ele se sente mais igual" (Ge2).

Para ser resolutivo o trabalho dos agentes comunitários de saúde é necessário que se efetive a intersetorialidade devido à complexidade de problemas identificados incluir ações que extrapolam a autonomia e governabilidade da área de saúde. Em alguns casos há uma facilitação.

“...Você fala com a assistente social, elas são muito dez. Elas participam da intersetorialidade junto com a gente (...) você pode mandar, se eu tiver uma cesta lá eu vou dar pra ela. Nós fizemos uma vez um projeto assim, bem simples de arborização no bairro. (...) chamamos o pessoal da $A R$, eles trouxeram um monte de mudinha. (...) fizemos até uma casinha, graças a Deus è̀ Secretaria de Cultura que está investindo na região" (Ga5).
Em outras situações, por ausência dessa ação conjunta a própria comunidade busca a construção de redes sociais para atender às necessidades das famílias.

“...Com a ajuda dos vizinhos que a gente está construindo um quarto, uma sala, um banheiro na cozinha. Porque a casa dela pegou fogo e ela se queimou. Então, os vizinhos (...) um deu o vaso sanitário (...), outro deu a janela, tem um movimento do comércio, o estacionamento ao lado deu areia, o outro deu a terra, o outro deu tijolo..." (Gc4).

O agente comunitário de saúde faz o reconhecimento dos problemas que existem na área em que ele vai trabalhar e que devem ser objeto de alguma intervenção, como por exemplo: locais em que há esgoto a céu aberto, focos de doenças infecto-contagiosas, violência doméstica, gravidez na adolescência, pacientes acamados ou que são totalmente dependentes etc. Isso faz parte da territorialização. Esse reconhecimento se faz por meio de elementos estéticos compartilhados pela comunidade e pelo agente comunitário de saúde.

Ocorre o que Rancière 16 (p. 15) chama de partilha do sensível: "Denomino partilha do sensível o sistema de evidências sensíveis que revela, ao mesmo tempo, a existência de um comum e dos recortes que nele definem lugares e partes respectivas. Uma partilha do sensível fixa, portanto, ao mesmo tempo, um comum partilhado e partes exclusivas. Essa repartição das partes $e$ dos lugares se funda numa partilha de espaços, tempos e tipos de atividade que determina propriamente a maneira como um comum se presta à participação e como uns e outros tomam parte nessa partilha".

Para que ocorra essa partilha é necessário que cada um que dela participa tenha direito à voz. Os agentes comunitários de saúde se percebem como a voz da comunidade dentro da unidade de saúde.

"A gente é o vínculo da população com o centro de saúde e muitas vezes eles pegam a gente $e$ perguntam coisas que às vezes eles tem vergonha de perguntar no centro de saúde, então (...) eles vêm pra gente pra pegar a informação correta ou querendo entender o que tá querendo dizer. Então a gente é o vínculo (...) e quando é reclamação também..." (Gd3).

"Eu vejo aquela fila enorme de pacientes, né (...) e eu fico pensando assim: 'e se fosse eu que tivesse ali?, ninguém vai atender?' (...) sendo que a gente conhece (...) tá vendo ali (...) aí vão falar 'ah, não quer fazer, né!'. Eu me sinto mal e acabo ajudando todo mundo!" (Gd4).

Ocorre uma partilha do sensível dos agentes comunitários de saúde com a população e os 
agentes estendem essa partilha para a unidade de saúde.

O fato de o agente comunitário de saúde morar na área de abrangência do serviço no qual atua lhe confere a possibilidade de conviver com a realidade e as práticas de saúde do bairro, conhecendo profundamente a população, tornando-se um representante da comunidade no serviço de saúde, aumentando o vínculo entre os profissionais de saúde e a comunidade, o que em certa medida contribui para a melhoria da atenção à saúde.

“...A população começou a ver assim, tem alguém da comunidade, alguém que é daqui, que eu conheço, que vai na mesma missa que eu, que freqüenta a mesma feira que eu, que é amigo do meu pai e assim por diante. Os profissionais do centro de saúde dificilmente trabalham na região que eles residem (...), os agentes de saúde, não, ele está ali, ele é fixo, ele é daquele centro de saúde, e é alguém da comunidade (...) quando a gente entrou eu ouvi falar assim: 'Nossa que legal! Você está trabalhando lá, então, quando eu precisar de alguma coisa eu posso te procurar'. As pessoas perceberam que tinha alguém dali, da comunidade que vive o mesmo problema que ela, a mesma dificuldade que ela, dentro do centro de saúde e que fosse uma referência para ela" (Gd5).

Outro aspecto importante do trabalho do agente comunitário de saúde é quanto aos vários papéis que assume perante a comunidade, indo muito além das atribuições definidas para tal função, por ser ele o representante do poder público e se sentir responsável pelas famílias que atende, a população o identifica como o articulador entre os problemas pessoais ou coletivos em situações de risco eminente.

“...É que o agente a cada momento ele é uma coisa, então eles chegam assim: Oi doutora! Aí no outro dia eles estão precisando de assistente social, (...) você é enfermeira, você é doutora, depende do dia. Você é assistente social, você é psicólogo, enfermeira padrão, médica (...) dentista, você vira até delegada, até uma crise assim: meu marido me bate, não refere mais a delegacia da mulher" (Ge6).

A capacitação dos agentes comunitários de saúde atendeu às diretrizes do PSF-Paidéia, no sentindo de trazer diversos conhecimentos em torno da questão do processo de saúde-doença, além de incorporar outros saberes presentes no cotidiano das famílias e no conhecimento de suas necessidades. É importante ressaltar que para a efetivação satisfatória desse programa é necessário que dentre outras questões, haja um trabalho em equipe, onde a diversidade de conhecimento e habilidades dos diversos profissionais que compõem as equipes de referência se complementem e enriqueçam o trabalho como um todo, contribuindo para que essas metas sejam alcançadas.

As falas evidenciaram que foram dois os aspectos para os quais a formação colaborou: o papel de articulador, o que foi feito ao se tornar a voz da comunidade e por dar voz a comunidade, e o fato de o agente comunitário de saúde ser mais livre para propor coisas para a comunidade, passear pela comunidade, ter maior autonomia, ao passo que os profissionais do centro de saúde estão mais atrelados às regras e aos protocolos de conduta.

\section{Considerações finais}

O agente comunitário de saúde desempenha o papel de mediador social, sendo considerado por Nogueira et al. 17 (p. 78), como: "um elo entre os objetivos das políticas sociais do Estado e os objetivos próprios ao modo de vida da comunidade; entre as necessidades de saúde e outros tipos de necessidades das pessoas; entre o conhecimento popular e o conhecimento científico sobre saúde, entre a capacidade de auto-ajuda própria da comunidade e os direitos sociais garantidos pelo Estado".

Neste trabalho encontramos essa função de elo. Mas eles apontam que seu papel vai além de um elo, uma vez que o papel desempenhado se manifesta quando o agente comunitário de saúde dá voz para a comunidade ou é a voz da comunidade dentro dos serviços de saúde. $\mathrm{Na}$ Declaração de Jacarta 18, o conceito inglês de empowerment foi traduzido para o português como sendo dar voz para a comunidade. Entendemos que era esse o significado utilizado pelos agentes comunitários de saúde quando eles disseram que eles, ou davam voz para a comunidade ou eram a voz da comunidade. A inserção deles se manifesta ao serem a voz da comunidade para dentro dos serviços de saúde mais do que o elo para a ligação entre os serviços de saúde e a comunidade.

O PSF-Paidéia incluiu o agente comunitário de saúde no sistema de saúde do Município de Campinas, sendo depositada uma grande expectativa no seu trabalho a ser desenvolvido junto às equipes de referência para reordenar as ações desenvolvidas nas unidades básicas de saúde e consolidar o modelo de saúde implantado. Diante da pesquisa realizada, pudemos constatar que esse profissional atua na perspectiva de efetivar as diretrizes estabelecidas, cumprindo o papel de interlocutor entre a comunidade e os serviços de saúde, ressignificando continuamente as práticas no cotidiano do seu trabalho. 
O trabalho do agente comunitário de saúde 2 não está pautado na doença, mas sim no sujeito enfermo ou com possibilidade de adoecer, ele considera o paciente como "sujeito singular", pertencente a uma família, a uma comunidade, ou organizações institucionais, ou seja, o território como espaço de intervenção. O agente comunitário de saúde tem a sensibilidade de ler, escutar e traduzir para as equipes de referência, as reais necessidades da população, encontradas em cada residência, em cada pessoa, em cada família e em cada comunidade.

Os núcleos de saúde coletiva fazem parte do rearranjo proposto para a reorganização da atenção à saúde, sendo considerados um recurso potente para ampliação das ações de promoção e de prevenção ${ }^{2}$. Os agentes comunitários de saúde participam desse colegiado, apoiando e buscando auxílio para o enfrentamento conjunto de problemas relacionados à vigilância à saúde, sendo esse espaço considerado privilegiado no sentido da construção coletiva.

O cadastramento das famílias é realizado exclusivamente pelos agentes comunitários de saúde de casa em casa, além do trabalho cartorial inerente a essa atividade, esse tem sido um momento que possibilita a inclusão do usuário e da família no sistema de saúde e a identificação dos dilemas que estão pairando naquele núcleo familiar.

Os agentes comunitários de saúde se sentem responsáveis não só pelos problemas identificados na comunidade, mas se solidarizam com o sofrimento das pessoas, ouvindo as demandas, buscando compreendê-las e realizando parcerias no sentido de encontrar soluções criativas e originais. O espaço em que eles vivem é o mesmo onde atuam, as pessoas de suas realidades sociais são as mesmas para quem dirigem suas ações de cuidado.

"Essa concordância de universo físico, social e psicológico, estimula o empenho de propor o bem viver desejado para o outro, como para si, numa ampliação de aspirações a nível biológico, relacional e sócio-político" 17 (p. 81).

Nesse sentido, podemos afirmar que o agente comunitário de saúde estabelece vínculo, estimulando a capacidade das pessoas para enfrentarem problemas a partir de suas condições concretas de vida.
Portanto, concluímos que a formação oferecida pela SMS foi determinante na construção das habilidades e competências dos agentes comunitários de saúde, consolidando as diretrizes do PSF-Paidéia. Entendemos que a formação é contínua na medida em que está permeada pelas relações concretas que operam realidades e que possibilita construir espaços coletivos para a reflexão e a avaliação de sentido dos atos produzidos no cotidiano.

Os agentes comunitários de saúde trazem à tona a necessidade de incorporar novos elementos à sua prática e aos seus conceitos, a partir de desconfortos experimentados no cotidiano do trabalho, percebendo que o modo de fazer é insuficiente para dar conta dos desafios postos. A vivência e a reflexão sobre as práticas vividas produzem insatisfação, levando à busca permanente de alternativas para enfrentar o desafio e produzir transformações na realidade concreta 19.

Sugerimos que os agentes comunitários de saúde sejam incluídos em processos de educação permanente, que de acordo com Ceccim 20 (p. 3) "traz em sua centralidade a porosidade à realidade mutável e mutante das ações e dos serviços de saúde, a sua ligação política com a formação de perfis profissionais e de serviços, a introdução de mecanismos, espaços e temas que geram autoanálise, autogestão, implicação, mudança institucional, enfim, pensamento (disruptura com instituídos, fórmulas ou modelos) e experimentação (em contexto, em afetividade - sendo afetado pela realidade)".

A partir da concepção adotada para efetivar a formação do agente comunitário de saúde, constatamos que a educação é permanente, visto que o lugar é dinâmico e as ações desenvolvidas nesse espaço são transitórias. O território, portanto, passa a ser considerado como um espaço privilegiado de interação, de diálogo, de reflexão, de tessitura do conhecimento, do ainda não sei, mas busco, do exercício da dúvida e da investigação como possibilidade de apropriação e de compreensão da realidade, de respeito e trabalho com as diferentes culturas, cultivando valores solidários e movimentos emancipatórios, onde os agentes comunitários de saúde se assumem como sujeitos transformadores. 


\section{Resumo}

O objetivo desse estudo é identificar as contribuições que o curso de formação de agente comunitário de saúde oferecido pela Secretaria Municipal de Saúde de Campinas, São Paulo, Brasil nos anos de 2001 a 2003, para a avaliação que esses fazem da sua inserção no território, bem como apontar o impacto que teve na sua prática profissional. Trata-se de uma pesquisa de natureza qualitativa em saúde, sendo utilizada a técnica de grupo focal, e para a análise dos dados empíricos utilizamos a análise de conteúdo temática. A formação do agente comunitário de saúde tinha por objetivo inserir um profissional capaz de refletir e intervir sobre sua realidade. O Programa Saúde da Família - Paidéia incluiu o agente comunitário de saúde no sistema de saúde, para reordenar as ações trabalhadas nas unidades básicas de saúde e consolidar o modelo de saúde implantado. Constatamos que a formação possibilitou que o agente comunitário de saúde assumisse o papel de sujeito educativo produzindo um conhecimento emancipatório, estimulando a reflexão e a capacidade de análise crítica, incluindo a prática diária como um dos determinantes de seu aprendizado, na busca de solucionar problemas na comunidade.

Serviços de Saúde Comunitária; Pessoal de Saúde; Programa Saúde da Família

\section{Referências}

1. Rolim LF, Lima PGA. Apoio ao Programa Saúde da Família. http://itd.bvs.br/itd-mod/public/scripts/ lhp/page_show_introduction.php? (acessado em 30/Out/2006).

2. Campos GWS. Saúde Paidéia. São Paulo: Editora Hucitec; 2003.

3. Secretaria Municipal de Saúde de Campinas/Coordenadoria Setorial das Relações de Trabalho/Centro de Educação dos Trabalhadores da Saúde. Capacitação Paidéia saúde da família no SUS Campinas: agente comunitário de saúde. v. 2. Campinas: Secretaria Municipal de Saúde de Campinas; 2004.

4. Secretaria Municipal de Saúde de Campinas/Coordenadoria Setorial das Relações de Trabalho/ Centro de Educação dos Trabalhadores da Saúde. Projeto de qualificação das relações de trabalho. Campinas: Secretaria Municipal de Saúde de Campinas; 2001.

\section{Colaboradores}

E. P. L. Nascimento trabalhou na coleta dos dados, transcrição das entrevistas, construção e análise dos resultados, pesquisa bibliográfica, elaboração do texto e revisão final. C. R S. Correa participou na construção e análise dos resultados, pesquisa bibliográfica, elaboração do texto e revisão final.
5. Freire P. Política e educação. São Paulo: Cortez Editora; 2001

6. Ministério da Saúde. Capacitação pedagógica para instrutor supervisor área da saúde. Brasília: Ministério da Saúde; 1989.

7. Berbel NAN. A problematização e a aprendizagem baseada em problemas: diferentes termos ou diferentes caminhos. Interface Comun Saúde Educ 1998; 2:139-54

8. Bueno SMV, Bagnato MHS, Oliveira MV, Costa FNA. Enfermeiro professor e o ensino médio em enfermagem. In: Anais do II Encontro de Formação de Professores de Ensino Médio em Enfermagem Política de Formação de Recursos Humanos de Nível Médio em Enfermagem. Ribeirão Preto: Gráfica São Gabriel; 1997. p. 103. 
9. Secretaria de Gestão do Trabalho e da Educação na Saúde, Ministério da Saúde. Proposta de formação do agente comunitário de saúde-habilitação profissional técnica. Brasília: Ministério da Saúde; 2004.

10. Gatti BA. Grupo focal na pesquisa em ciências sociais e humanas. Brasília: Liber Livro Editora; 2005. (Série Pesquisa em Educação).

11. Westphal MF, Bógus CM, Faria MM. Grupos focais: experiências precursoras em programas educativos em saúde no Brasil. Bol Oficina Sanit Panam 1996; 120:472-82.

12. Bardin L. Análise de conteúdo. 3ạ Ed. Lisboa: Edições 70; 2004.

13. Minayo MCS. O desafio do conhecimento: pesquisa qualitativa em saúde. 6ạ Ed. São Paulo: Editora Hucitec/Rio de Janeiro: ABRASCO; 1999.

14. Benevides R. Dispositivos em ação: o grupo. Cadernos de Subjetividade 1996; 1:97-106.
15. Nascimento EPL. As enfermeiras e suas práticas na rede básica de saúde de Campinas nas décadas de 70 e 80 [Dissertação de Mestrado]. Campinas: Universidade Estadual de Campinas; 2002.

16. Rancière J. A partilha do sensível: estética e política. São Paulo: EXO Experimental/Editora 34; 2005.

17. Nogueira RP, Silva FB, Ramos ZVO. A vinculação institucional de um trabalhador sui generis: o agente comunitário de saúde. Rio de Janeiro: Instituto de Pesquisa Econômica Aplicada; 2000. (Texto para Discussão, 735).

18. Organização Mundial da Saúde. Declaração de Jakarta. In: Buss PM, organizador. Promoção da saúde e saúde pública. Rio de Janeiro: Escola Nacional de Saúde Pública Sergio Arouca, Fundação Oswaldo Cruz; 1997. p. 174-8.

19. Bachilli RG, organizadora. A identidade do agente comunitário de saúde: a releitura dos sujeitos. Cerquilho: Edição das Autoras; 2006.

20. Ceccin RB. Educação permanente em saúde: desafio ambicioso e necessário. Interface Comun Saúde Educ 2005; 9:161-77.

Recebido em 21/Nov/2006

Versão final reapresentada em 13/Set/2007 Aprovado em 27/Set/2007 